\title{
Screening for Intimate Partner Violence in a Primary Care Setting: The Validity of "Feeling Safe at Home" and Prevalence Results
}

\author{
Robert L. Peralta, PhD, and Michael F. Fleming, MD, MPH
}

Background: We conducted a study to assess the validity of a screening question commonly used to detect intimate partner violence (IPV) in primary care settings. We also analyzed prevalence and risk factors of IPV.

Methods: We used an embedded domestic violence detection instrument in a general health questionnaire at one family medicine clinic. Questionnaire scales included a modified version of the Conflict Tactics Scale (CTS), depression and alcohol use scales, and a personal safety question ("Do you feel safe at home?"). We assessed the sensitivity, specificity, and predictive value of the personal safety question in our sample using responses to the modified CTS and the personal safety question. Three hundred ninety-nine female patients over the age of 18 completed the survey.

Results: CTS results revealed $44.3 \%$ of women experienced any violence, $43.5 \%$ of women experienced psychological violence in the presence or absence of physical violence, and $10.3 \%$ experienced physical violence in the presence or absence of psychological violence in the previous 90 days. The sensitivity of a single question used to detect any violence ("Do you feel safe at home?") was 8.8\%; the specificity was $91.2 \%$. Racial identity, marital status, and depression influenced the likelihood of IPV.

Conclusions: These preliminary results call into question the utility of the safety question "Do you feel safe at home" for detecting cases of intimate partner violence in a primary care sample. ( $\mathrm{J}$ Am Board Fam Pract 2003;16:525-32.)

Intimate partner violence (IPV) has been increasingly recognized as a public health problem associated with serious medical, family, and societal effects. ${ }^{1}$ These effects include injury, reproductive health consequences, mental health problems, family problems, and high rates of health care utilization. $^{2-4}$ Mounting research suggests that many abused victims seek health care for injuries and other health problems related to abuse. Health care costs have been found to be higher in women who report partner violence. ${ }^{5}$ By most estimates, 2 to 4 million adult women are battered in the United States each year. ${ }^{6}$ Because intimate partner violence is a health problem, with documented shortand long-term health consequences, health care workers have a responsibility and unique opportunity to identify IPV in clinical settings.

Submitted, revised, 2 July 2003.

From the Department of Justice, Law \& Society, School of Public Affairs, American University, Washington, DC (RLP), and Department of Family Medicine, University of Wisconsin-Madison, Madison (MFF). Address correspondence to Robert L. Peralta, Department of Sociology, University of Akron, Akron, OH 44325-1901.
Advocates and other IPV experts have specifically recommended that physicians should routinely screen for and identify primary care patients whose partners are abusive. ${ }^{7-9}$ Many have called for using a single question designed to detect intimate partner violence embedded within general health behavior surveys. ${ }^{10-12}$ "Safety" questions (eg, "Do you feel safe at home?"; Do you ever feel afraid of your partner?"; "How are things at home?") have been suggested for use in waiting rooms to screen patients for IPV. ${ }^{13}$

Two published studies have compared a simple partner violence screening instrument to the accepted standard, the Conflict Tactics Scale (CTS) ${ }^{14,15}$ Of these 2 studies, only the study by Feldhaus et $\mathrm{al}^{16}$ assessed the usefulness of "Safety" questions. The CTS has been widely used as the standard instrument for detecting intimate partner violence. Researchers have relied on the instrument in primary care samples and report adequate validity, sensitivity, specificity, and predictive values in primary care populations. ${ }^{14,15}$

As questions about intimate partner violence increasingly become the subject matter of health behavior researchers, it continues to be of importance 
Couples use many different ways of trying to settle their differences. The following things may happen to you during an argument with your boyfriend, husband, or partner. Please mark how many times in the last 3 months

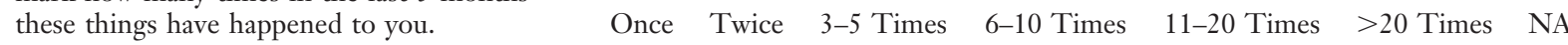

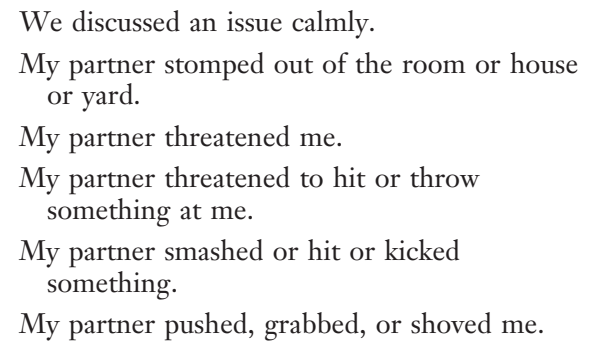

to gather prevalence data and the demographic correlates of this type of victimization for different populations. ${ }^{17}$ Gathering these data serve first to alert health professionals and researchers about the scope of the problem and second to illuminate the social conditions that are often associated with these types of harmful behaviors. The purpose of the study is test the validity of the safety question compared with the CTS, report prevalence estimates for women seeking primary care, and identify predictors of intimate partner violence for the sample studied.

\section{Methods}

\section{Participants and Survey Administration}

The study was conducted between April and July 2002 in one urban family medicine clinic in Madison, Wisconsin (population 197,000). Permission was granted to conduct the study by the University of Wisconsin human subjects review committee. English-speaking women between the ages of 18 and 36 were invited to participate in the confidential survey. One of 2 research associates approached all women in the waiting area of the clinic with information about the study.

The study was described to each potential participant as a survey about women's health conducted by the University of Wisconsin. Women were told that the study was intended for women between 18 and 36 years of age and was completely voluntary. Women were told that they could end their participation at any time without penalty or could choose not to respond to specific questions. Gift certificates worth $\$ 5$ toward a meal were of- fered as an incentive for respondents to participate. Participants completed surveys privately and individually. When finished, surveys were mixed with other completed surveys in an envelope to facilitate confidentiality. A minority of women refused with no explanation. The rate of patient refusal was $12 \%$. Most refusals were based on patients reporting not feeling well enough to participate, lack of adequate English speaking/reading ability, or child care responsibilities. Women are classified in the present analysis as white, black and other. "Other" refers to women of Hispanic, Asian, and Native American descent, of which too few participated for meaningful analysis to be conducted.

\section{Survey Instrument}

The instrument contained a total of 44 items and could be completed in 15 to 20 minutes. Questions were specifically designed to estimate 90 -day prevalence rates. The survey instrument included: (a) a "Safety" question ("In the past 3 months, did you feel safe at home?"); (b) a modified version of the Conflict Tactics Scale (CTS) consisting of 6 original CTS questions (Table 1); (c) the Center for Epidemiology Studies-Depression Scale (CES-D); (d) alcohol consumption was measured by asking about the average number of days per week alcohol was consumed and the average number of drinks consumed when drinking; (e) demographic questions; and ( $\mathrm{f}$ ) questions regarding general medical history.

We adopted a modified version of the CTS for 3 reasons. First, the human subjects review board 
thought that questions from the original CTS were too sensitive and requested modification. Next, we modified the CTS to increase the response rate by adopting a less sensitive or intrusive questionnaire. Finally, a shorter scale was adopted to reduce the time and effort of patients awaiting primary care. The CES-D is an instrument that was developed by the National Institute of Mental Health to detect major or clinical depression in adolescents and adults. The questions are easy to answer and cover most of the areas included in the diagnostic criteria for depression. It has been used in urban and rural populations and in cross-cultural studies of depression. Studies using the CES-D indicate that it has very good internal consistency, acceptable testretest stability, and construct validity. ${ }^{18,19}$ Finally, we collected demographic information to provide further data on the correlates of intimate partner violence. We wanted to examine the effects of variables traditionally collected in epidemiologic studies of intimate partner violence. Race, education, martial status, and whether or not the patient had children living at home were used as independent variables.

\section{Definitions}

Women were defined as experiencing psychological violence if they indicated that their partner either "stomped out of the room," "threatened," "threatened to hit or throw something at me," or "smashed or kicked something" at least once in the past 3 months. Women were defined as experiencing physical violence if they indicated being "pushed, grabbed, or shoved" at least once in the past 3 months. Psychological and physical violence are not necessarily mutually exclusive. Responses from women screening positive for psychological violence and physical violence on the modified CTS were compared with their responses to the "Safety" question ("In the past 3 months, did you feel safe at home?"). Indications of feeling "unsafe" at home in the past 3 months were considered positive screens for IPV. Women who reported feeling "safe" at home were considered negative for IPV. Screening positive for depression using the CES-D scale was defined here as answering positively to at least four of 10 questions that inquire about feelings of depression, sadness, and loneliness.

\section{Statistical Analysis}

Data were summarized and statistically analyzed using SAS software. Frequency distributions and summary statistics were calculated for variables of interest. In the descriptive analysis, frequency distributions of study variables were examined and the prevalence of psychological and physical violence was determined. $\chi^{2}$ tests were used to assess the associations of demographic variables with types of violence. Race (white versus nonwhite), education, marital status, and depression were then entered into a logistic regression model to determine which demographic factors independently predicted physical and psychological violence. Sensitivity, specificity, predictive values, and likelihood ratios were calculated.

Sensitivity was calculated on 3 different scores. We calculated sensitivity for physical violence, psychological violence, and any form of violence (physical and or psychological violence) by comparing a positive response on the safety question to a positive score on the CTS. Specificity was calculated on negative responses. Specificity and sensitivity calculations were used to determine the statistical relationship between responses to modified CTS items and the single question "do you feel safe at home?"

\section{Results}

Table 2 presents the demographics of the sample. The table compares those who self-report recent violence victimization with those who do not selfreport recent violence victimization. Specifically, the table is divided into women who report recent psychological and/or physical victimization and those who reported no victimization at all. Three hundred ninety-nine women participated in the study. Sixty-one percent of respondents were white and $26 \%$ were African American. Eighty-one percent had more than a high school education. Results of the CES-D scale indicated $23.4 \%$ of the sample screened positive for depression in the past 90 days. Four percent of all female respondents reported using alcohol 4 or more times per week. Slightly more than 1 of 10 women in the study $(13.6 \%)$ reported drinking 4 or more drinks per sitting on average even if it they drank only once per week. The vast majority of respondents (93.9\%) reported feeling safe at home. Of those who reported feeling safe at home, $43 \%$ experi- 
Table 2. Sample Characteristics, Feeling Safe at Home by Self-Reported Experiences with Violence \% (N = 399)

\begin{tabular}{|c|c|c|c|}
\hline Demographics & $\begin{array}{l}\text { Positive Screens for Physical } \\
\text { and/or Psychological } \\
\text { Violence }(\mathrm{N}=174)\end{array}$ & $\begin{array}{l}\text { Negative Screens for Physical } \\
\text { and/or Psychological } \\
\text { Violence }(\mathrm{N}=214)\end{array}$ & Total $\mathrm{N}^{*}$ \\
\hline \multicolumn{4}{|l|}{ Race } \\
\hline Black & 44.2 & 55.8 & 104 \\
\hline White & 43.9 & 56.1 & 237 \\
\hline Other & 45.2 & 54.8 & 31 \\
\hline \multicolumn{4}{|l|}{ Education } \\
\hline High school or less & 49.7 & 50.3 & 161 \\
\hline Some college & 46.8 & 53.2 & 139 \\
\hline College or more & 30.0 & 70.0 & 80 \\
\hline \multicolumn{4}{|l|}{ Marriage } \\
\hline Married & 41.5 & 58.5 & 135 \\
\hline Other & 46.7 & 53.3 & 242 \\
\hline \multicolumn{4}{|l|}{ Children at home } \\
\hline Yes & 49.3 & 50.7 & 229 \\
\hline No & 36.9 & 63.1 & 152 \\
\hline \multicolumn{4}{|c|}{ Drinking episodes per week } \\
\hline None & 42.8 & 57.2 & 152 \\
\hline $1-3$ & 45.9 & 54.1 & 220 \\
\hline $4+$ & 43.7 & 56.3 & 16 \\
\hline \multicolumn{4}{|c|}{ Average number of drinks per episode } \\
\hline None & 42.2 & 57.6 & 151 \\
\hline $1-3$ & 45.9 & 54.1 & 183 \\
\hline $4+$ & 47.2 & 52.8 & 53 \\
\hline \multicolumn{4}{|c|}{ Did you feel safe at home? } \\
\hline Yes & 43.2 & 56.8 & 361 \\
\hline No & 62.5 & 37.5 & 24 \\
\hline \multicolumn{4}{|l|}{ CES-D } \\
\hline Depression & 53.9 & 46.1 & 89 \\
\hline No depression & 39.9 & 60.1 & 291 \\
\hline
\end{tabular}

* May not sum to 399 because of missing data.

enced physical and or psychological abuse (any violence) in the past 3 months. Women who had 4 or more drinks per sitting were slightly more likely to report IPV compared with women who had less alcohol per sitting (47.2\% compared with $42.8 \%$ ).

Table 3 reports the frequency of violence vic-

Table 3. Prevalence of Psychological and Physical Violence-Past 90 Days Based on 6 Questions from the CTS \% $(\mathrm{N}=399)$

\begin{tabular}{|c|c|c|c|c|}
\hline & All & White & Black & Other \\
\hline Any type of violence & $44.3(n=164)$ & $44.1(\mathrm{n}=104)$ & $44.7(n=46)$ & $45.1(\mathrm{n}=14)$ \\
\hline $\begin{array}{l}\text { Psychological violence with or without } \\
\text { physical violence }\end{array}$ & $43.5(n=162)$ & $43.5(n=103)$ & $43.3(\mathrm{n}=45)$ & $45.2(\mathrm{n}=14)$ \\
\hline $\begin{array}{l}\text { Physical violence with or without } \\
\text { psychological violence* }\end{array}$ & $10.3(\mathrm{n}=38)$ & $6.8(\mathrm{n}=16)$ & $19.6(\mathrm{n}=20)$ & $6.5(\mathrm{n}=2)$ \\
\hline \multicolumn{5}{|l|}{ Type of violence experienced } \\
\hline No violence $\dagger$ & $55.9(\mathrm{n}=208)$ & $56.1(\mathrm{n}=133)$ & $55.7(\mathrm{n}=58)$ & $54.8(\mathrm{n}=17)$ \\
\hline Only psychological violence $\ddagger \S$ & $34.1(\mathrm{n}=126)$ & $37.1(\mathrm{n}=88)$ & $25(\mathrm{n}=26)$ & $38.7(\mathrm{n}=12)$ \\
\hline Only physical violence $\|$ & $0.5(\mathrm{n}=2)$ & $0.42(\mathrm{n}=1)$ & $0.96(\mathrm{n}=1)$ & $0.0(\mathrm{n}=0)$ \\
\hline Both psychological and physical violence $\neq \mathbb{I}$ & $9.7(\mathrm{n}=36)$ & $6.3(\mathrm{n}=15)$ & $18.3(\mathrm{n}=19)$ & $6.5(n=2)$ \\
\hline
\end{tabular}

${ }^{*} \mathrm{p}<.01$

+ Women who report no psychological or physical violence.

${ }^{\ddagger} \mathrm{p}<.05$

$\$$ Women who report psychological violence in absence of physical violence.

"Women who reported physical violence in the absence of psychological violence.

"II Women who reported both physical and psychological violence. 
Table 4. Sensitivity and Specificity Results for 'Do You Feel Safe at Home?' Compared with Results from the Modified CTS for Physical and or Psychological Violence $(\mathrm{N}=399) *$

\begin{tabular}{lll}
\hline & - CTS $(\mathrm{N}=214)$ & $+\mathrm{CTS}(\mathrm{N}=171)$ \\
\hline Feel Unsafe $(\mathrm{N}=24)$ & False Positive $4.2 \%$ & True Positive 8.8\% \\
Feel Safe $(\mathrm{N}=361)$ & True Negative $95.8 \%$ & False Negative 91.2\% \\
\hline
\end{tabular}

* May not add to 399 because of missing data. Sensitivity, 8.8\%; specificity, 95.8\%; likelihood ratio, 3.4 .

timization by race. When psychological and physical histories of violence are combined, few differences emerge by demographic characteristics. Results of the modified CTS instrument indicated $44.3 \%$ of the sample reported any (psychological or physical) violent victimization in the past 90 days. There were no significant differences by race on this measure. When differentiating types of violence, $34.1 \%$ of the entire sample disclosed having experienced only psychological violence. Less than $1 \%$ disclosed only physical violence without psychological violence in the past 90 days, whereas 9.7\% reported both physical and psychological violence. Statistically significant differences $(P<.05)$ did emerge when examining specific aspects of violence by race. Black women were more likely to self-report experiencing physical violence (with or without psychological violence) compared with white women. Nearly 20\% (19.6\%) of black women report physical violence in the past 90 days compared with $6.8 \%$ of white women and $6.5 \%$ of "other women." These analyses suggest when violence is differentiated (psychological versus physical), racial differences in 30-day prevalence figures emerge.

Tables 4 to 6 report sensitivity and specificity proportions. They were derived by comparing responses to modified CTS questions differentiated by physical and or psychological violence to a safety question ("In the past 90 days, did you feel safe at home?"). The sensitivity or measure of accuracy for predicting any violence (physical and or psychological violence) was $8.8 \%$ (Table 4). That is, only
$8.8 \%$ of those who experienced any form of violence did not indicate feeling safe at home. Not feeling safe at home is presumed to detect those victimized by intimate partner violence. The specificity or measure of accuracy for predicting no violence for the "any violence" category was $95.8 \%$. Stated another way, $95.8 \%$ of those who did not experience violence in the past 90 days as measured by the modified CTS reported feeling safe at home in the past 90 days. For any type of violence, the safety question seems to have low predictive accuracy but high specificity. Sensitivity and specificity proportions for physical violence (with or without psychological violence present) are $15 \%$ and $94.7 \%$, respectively (Table 5). Stated another way, for cases involving physical violence, the safety question's measure of accuracy for predicting violence is better compared with instances when any type of violence is present. Finally, the sensitivity of the question for psychological violence with or without physical violence was $8.8 \%$ and the specificity was $95.9 \%$. Thus, the measures of accuracy for psychological violence are comparable with those for the "any violence" category.

Finally, logistic regression models were used to predict psychological and physical intimate partner violence. Logistic regressions results for physical intimate partner violence can be found in Table 7 . The model predicting physical violence with or without the presence of psychological violence was significant $(P<.01)$. Models predicting psychological violence and any violence were not significant $(P<.05)$. Respondents who were white, married,

Table 5. Sensitivity and Specificity Results for 'Do You Feel Safe at Home?' Compared with Results from the Modified CTS for Physical Violence with or without Psychological Violence $(\mathbf{N}=399)^{*}$

\begin{tabular}{lll}
\hline & - CTS $(\mathrm{N}=342)$ & + CTS $(\mathrm{N}=40)$ \\
\hline Feel Unsafe $(\mathrm{N}=24)$ & False Positive 5.3\% & True Positive 15\% \\
Feel Safe $(\mathrm{N}=358)$ & True Negative $94.7 \%$ & False Negative $85 \%$ \\
\hline
\end{tabular}

* May not add to 399 due to missing data. Sensitivity, 15\%; specificity, 94.7\%; likelihood ratio, 4.4 . 
Table 6. Sensitivity and Specificity Results for 'Do You Feel Safe at Home?' Compared with Results from the Modified CTS for Psychological Violence with or without Physical Violence $(\mathbf{N}=399) *$

\begin{tabular}{lll}
\hline & - CTS $(\mathrm{N}=218)$ & $+\mathrm{CTS}(\mathrm{N}=169)$ \\
\hline Feel Unsafe $(\mathrm{N}=24)$ & False Positive $4.1 \%$ & True Positive 8.9\% \\
Feel Safe $(\mathrm{N}=363)$ & True Negative $95.9 \%$ & False Negative 91.1\% \\
\hline
\end{tabular}

* May not add to 399 due to missing data. Sensitivity, 8.9\%; specificity, 95.9\%; likelihood ratio, 3.7.

and who did not screen positive for depression on the CES-D scale were less likely to have experienced physical violence in the past 90 days. The odds of self-reporting physical violence for black women were 3.57 times than for white women, 3.13 times greater for women who were not married compared with married women, and 3.14 greater for women who screened positive for depression compared with those who did not screen positive for depression.

\section{Discussion}

We found that women in a primary care setting willingly answered questions about intimate partner violence, fear, safety, depression, and selfesteem. Women disclosed psychological and physical aggression at rates similar to large, representative studies with physical violence prevalence rates of $6 \%$ to $11 \%{ }^{6}$. Racial differences also emerged for physical violence but not for psychological violence, with black women more likely to report physical violence.

The present study tested a single safety question against a standard intimate partner violence instru- ment to estimate its specificity and sensitivity. Whereas advocates and IPV experts have called for this type of screening, ${ }^{2,7,10}$ few studies have tested the efficacy of safety questions in primary care settings. The diverse sample of respondents in this study yields important insight into ethnic and racial differences in the prevalence of intimate partner violence and insight into the validity of a particular safety question. Results suggest women who are in abusive relationships may not define their home environments as "unsafe." For most screening instruments, the principal goal is to maximize sensitivity. In the current study, the sensitivity of the safety question was poor. The false negatives are of clinical concern. Of the 40 women who were experiencing physical violence, 34 (80\%) reported feeling safe at home. In other words, despite experiencing physical victimization, women stated they felt safe at home. Whether they are at risk for escalating nonphysical or physical abuse is unknown.

Published studies have examined the utility of 2 to 3 brief questions designed to detect intimate partner violence using the CTS as a comparison

Table 7. Logistic Model Predicting Physical Violence with or without Psychological Violence*

\begin{tabular}{|c|c|c|c|c|}
\hline & $\mathrm{B}$ & $\mathrm{SE}$ & Odds & $95 \% \mathrm{CI}$ \\
\hline Intercept $^{\dagger}$ & -1.80 & 0.58 & & \\
\hline White ${ }^{\S}$ & -1.26 & 0.46 & 0.28 & $0.12-0.69$ \\
\hline Other & -1.39 & 0.84 & 0.25 & $0.05-1.30$ \\
\hline Some college & 0.01 & 0.42 & 1.01 & $0.44-2.32$ \\
\hline College or more & -0.57 & 0.82 & 0.57 & $0.11-2.84$ \\
\hline Drink $1-3$ & -0.46 & 0.44 & 0.63 & $0.27-1.48$ \\
\hline Drink $\geq 4$ & 0.82 & 0.52 & 2.27 & $0.82-6.25$ \\
\hline Married $^{\dagger}$ & -1.14 & 0.53 & 0.32 & $0.11-0.91$ \\
\hline Children living at home & 0.53 & 0.47 & 1.71 & $0.68-4.30$ \\
\hline Depression $^{\dagger}$ & 1.14 & .41 & 3.14 & $1.40-7.05$ \\
\hline
\end{tabular}

CI, confidence interval; OR, odds ratio; SE, standard error

${ }^{*} \mathrm{~L} 2=37.2 ; \mathrm{df}=8 ; p<.00$.

${ }^{\S} p<-.05$.

$+p<.00$. 
criterion. ${ }^{16,20}$ Using a series of 2 to 3 contextualized, violence-specific questions (often derived from the CTS), these studies report promising results for brief and effective screening of intimate partner violence. Feldhaus et $\mathrm{al}^{16}$ administered a 3-question partner violence screen (PVS) against 2 detailed standard violence measures, the Index of Spouse Abuse (ISA) ${ }^{21}$ and the CTS, in hospitalbased emergency departments. The PVS incorporated 2 dimensions of partner violence: one question addressed physical violence (eg, "Have you been hit, kicked, punched, or otherwise hurt by someone within the past year? If so, by whom?"). Two questions addressed a woman's perception of her safety (eg, "Do you feel safe in your current relationship?" and "Is there a partner from a previous relationship who is making you feel unsafe now?"). Women were first verbally administered the PVS. Afterward, the ISA was administered in written format and the CTS in verbal format. Results from this study revealed that the simple physical abuse question ("Have you been hit, kicked, punched, or otherwise hurt by someone within the past year? If so, by whom?") was more sensitive and specific than the questions regarding safety, compared with both the ISA and CTS (sensitivity was $48.4 \%$ and $39.7 \%$ respectively; specificity was $87.6 \%$ and $87.4 \%$, respectively). Moreover, the physical abuse question detected almost as many of the abused patients as the overall PVS with improved specificity.

There are several important limitations to our study. This study does not report responses that might have resulted from using ordinary circumstances in a primary care setting because participants received a small payment for their participation. In addition, not all women who were eligible for the study agreed to participate. Unrecognized selection bias may have occurred because of the voluntary nature of the study. Nonparticipants and participants, however, were similar in age and race. Respondents may have differed in other unmeasured characteristics, such as alcohol history, education, and relationship status. The written format of the instrument used may have presented both literacy and privacy problems for participants. The modified CTS may not be a valid standard by which to measure the specificity and sensitivity of the "safety" question. The original CTS was designed to measure violence and not necessarily to screen for violence. The data are based on self- reports that were not verified. Finally, our study was limited to one urban family medicine clinic and to English-speaking women; the performance of the "safety" question may be different in other clinical settings. This work, however, is a necessary first step in addressing the validity of a commonly used "safety" question used by primary care settings to detect intimate partner violence.

Additional research on the specificity and sensitivity of safety questions is needed to establish more fully whether questions such as these are appropriate for clinical screening purposes. Finally, sexual assault is an important aspect of partner violence. Our screen did not inquire explicitly about sexual assault or "marital rape." Further research is needed to investigate this dimension of partner violence. It is unknown why women self-reporting violence in the present sample did not report feeling unsafe at home. Perhaps the violence experienced by these women was not defined as threatening because the violence was in the context of an intimate relationship. Alternatively, women may interpret the question of feeling safe at home as a matter of neighborhood "street" crime such as burglary, which are perceived to involve strangers. The study demonstrates that the safety question lacks reference to a relationship and, as discussed above, the current relationship may not be the troublesome one. Often, a previous partner poses the greatest risk in cases of IPV.

The health care system has been criticized of late for not fully participating in prevention and intervention efforts. Physicians cite many barriers to effectively treating intimate partner violence, including lack of adequate training, fear of legal recourse, and lack of time. ${ }^{22}$ Thus far, screening instruments for intimate partner violence have been widely adopted as part of a growing effort by the medical community to address the health issue of intimate partner violence. ${ }^{23}$ Many of these screening and assessment tools include the question "Do you feel safe at home?" Although at face value this question seems to be appropriate for women facing violence at the hands of an intimate partner, research has failed to address its validity. The present research findings raise concerns about the validity of safety questions (ie, "do you feel safe at home?") used in screening for intimate partner violence. For IPV screening procedures, specific questions about IPV that are relationship-oriented are recommended. 
We thank the Department of Family Medicine at the University of Wisconsin-Madison for the departmental grant that supported this research.

\section{References}

1. Campbell JC, Soeken K. Women's responses to battering over time. J Interpers Violence 1999; 14:21-41.

2. Gerbert B, Johnston K, Caspers N, Bleecker T, Woods A, Rosenbaum A. Experiences of battered women in health care settings: a qualitative study. Women Health 1996;24:1-17.

3. Campbell JC, Woods A, Chouaf KL, Parker B. Reproductive health consequences of intimate partner violence. Clin Nurs Res 2000;9:217-37.

4. Campbell JC. Forced sex and intimate partner violence: effects on women's risk and women's health. Violence against Women 1999;5:1017-36.

5. Wisner CL, Gilmer TP, Saltzman LE, Zink, TM. Intimate partner violence against women: do victims cost health plans more? J Fam Pract 1999;48: 439-43.

6. Jones AS, Gielen AC, Campbell JC, et al. Annual and lifetime prevalence of partner abuse in a sample of female HMO enrollees. Womens Health Issues 1999;9:295-305.

7. Ashur ML. Asking about domestic violence: SAFE questions [letter]. JAMA 1993;269:2367.

8. Gerbert B, Caspers N, Milliken N, Berlin M, Bronstone A, Moe, J. Interventions that help victims of domestic violence. J Fam Pract 2000;49:889-95.

9. Hamberger LK, Ambuel B, Marbella A, Donze, J. Physician interaction with battered women: the women's perspective. Arch Fam Med 1998;7: 575-82.

10. Freund KM, Bak SM, Blackhall L. Identifying domestic violence in primary care practice. J Gen Intern Med 1996;11:44-6.

11. Gerbert B, Moe J, Caspers N, et al. Physicians' response to victims of domestic violence: toward a model of care. Women Health 2002;35:1-22.

12. Neufeld B. SAFE questions: overcoming barriers to the detection of domestic violence. Am Fam Physician 1996;53:2575-80.
13. Gerbert B, Moe J, Caspers N. Simplifying physicians' response to domestic violence. West J Med 2000;172:329-31.

14. Newton RR, Connelly C, Landsverk JA. An examination of measurement characteristics and factoral validity of the Revised Conflict Tactics Scale. Educ Psychol Meas 2001;61:317-35.

15. Oreil KA, Fleming MF. Screening men for intimate partner violence in a primary care setting: a new strategy for detecting domestic violence. J Fam Pract 1998;46:493-8.

16. Feldhaus KM, Koziol-McLain J, Amsbury HL, Norton IM, Lowenstein SR, Abbott JT. Accuracy of 3 brief screening questions for detecting partner violence in the emergency department. JAMA 1997; 277:1357-61.

17. Cruz JM, Peralta RL. Family violence and substance use: the perceived effects of substance use within gay male relationships. Violence Vict 2001;16:161-172.

18. Hybels CF, Blazer DG, Pieper CF. Toward a threshold for subthreshold depression: an analysis of correlates of depression by severity of symptoms using data from an elderly community sample. Gerontologist 2001;41:357-65.

19. Greenfield T, Rehm J, Rogers JD. Effects of depression and social integration on the relationship between alcohol consumption and all-cause mortality. Addiction 2002;97:29-38.

20. McFarlane J, Greenberg L, Weltge A, Watson M. Identification of abuse in emergency departments: effectiveness of a two-question screening tool. J Emerg Nurs 1995;21:391-4.

21. Hudson WW, McIntosh SR. The assessment of spouse abuse: 2 quantifiable dimensions. J Marriage Fam 1981;43:873-88.

22. Gerbert B, Caspers N, Bronstone A, Moe J, Abercrombie P. A qualitative analysis of how physicians with expertise in domestic violence approach the identification of victims. Ann Intern Med 1999;131: 578-84.

23. Dearwater SR, Coben JH, Campbell JC, et al. Prevalence of domestic violence in women treated at community hospital emergency departments. JAMA 1998;280:433-8. 